\title{
Effects of Eccentric Strength Training's Time on Daily Plasma Testosterone Levels among Tunisian Sedentary Athletes
}

\author{
Salah SOUISSI ${ }^{1}$; Nasr CHALGHAF ${ }^{1}$; Fairouz AZAIEZ ${ }^{1}$; Foued CHEOUR ${ }^{2}$ \\ ${ }^{I}$ High Institute of Sport and Physical Education of Sfax. Tunisia \\ ${ }^{2}$ High Institute of Applied Biology of Medenine. Tunisia
}

\begin{abstract}
This study aims to evaluate the effects of the eccentric physical training's time on daily plasma concentrations of testosterone among sedentary athletes. Sixty male athletes, with homogeneous age, size and weight were selected for the study during three months. They were subjects to a strength training of the extensor and flexor muscles of the knee. After they were divided in two groups of thirty subjects and then had physical training either in the morning between 6 and 7, or in the evening, between 16 and 17. The dosage of testosterone on each athlete was performed before and after submission to an eccentric physical program at the antecubital vein in a restful sitting. Our results have shown that eccentric physical training induces the increase of this steroid hormone in the two groups of athletes and the training in the evening promotes better its production. Our results also showed that the rate of this androgen drop significantly during the day in both groups of athletes trained in the morning or in the evening as well as their respective controls. However, the decline was even more pronounced for subjects trained in the morning.
\end{abstract}

Keywords: testosterone; training time; eccentric training.

\section{Introduction}

The strength training is very specific (Sale et al., 1992). Indeed, highlighting its effects can't be done effectively only by using during the evaluation tests, the same patterns and speed of movement as those implemented at the workout itself (Sale and Dougall, 1981). Thus, it was suggested that the adaptations to training may depend on the time of its completion (Souissi et al., 2002). The theoretical basis of the temporal specificity of training is based on the fact that the majority of physiological parameters and adaptations to acute exercise have a circadian rhythm (Hill et al., 1989). Indeed, the circadian rhythm of muscle's strength is now clearly identified with an observed acrophase between 17 and 19 hours, a batyphase between 4 and 6 hours and a range of 3 to $21.2 \%$ depending on the population, the muscle group and also the experimental conditions (Callard et al., 2000; Gauthier et al., 2001).

The circadian rhythm of muscular strength oscillates in phase with the anaerobic performance during events such as sprints (Falgairette et al., 2003; Racinais et al., 2005), load/speed (Bernard et al., 1998.) or wingate (Souissi et al., 2003). Therefore, the gain of strength by following a muscle building are the result of a combination of multiple events, starting from control centers of the corticospinal areas and leading to the actuation bridges unions at the periphery. The endocrine system may also play a role in the strength gain. Among the hormones secreted by the endocrine glands, testosterone is often mentioned in studies of hormonal adaptations to strength training (Kraemer et al., 1990).

The testosterone is the main hormone secreted by the testicles. It plays an important role in growth, development and maturation of the male skeletal system. It also contributes to the growth of skeletal muscle and the development of strength (Ferrando et al., 1998). Infact, the development of the latter is often positively correlated with its serum's concentration (Bhasin et al., 2001; Kvorning et al., 2006). Kraemer et al. (2005) noted that the concentrations of this hormone at rest reflect the anabolic status of muscle tissue. The objective of our study was to verify the effects of time strength training with eccentric types among the sedentary athletes on the daily changes of the plasma concentrations of testosterone.

\section{Materials and Methods}

Sixty male volunteers' athletes have been carefully selected to participate in the study. Their average's age, height and weight were respectively ordered as following: $21.82 \pm 0.71$ years, $1.74 \pm 0.04 \mathrm{~m}$ and $71 \pm 2.82$ $\mathrm{kg}$. The participants were divided on two groups of thirty athletes. The first group has always been put to tests of strength along twelve weeks in the morning's hours between 7 and 8 . While, the second one was starting at the afternoon hours between 16 and 17. Throughout the period of training, athletes followed a strict hygiene and similar life.

The selected athletes for our study have a physical training respectively in concentric and eccentric during 4 and 8 weeks. They have a strength training of the extensor and the flexor muscles of the knee with three sessions per week. Two successive sessions were separated by at least 48 hours. Three units of the gym of 
the Higher Institute of Sport and Physical Education of Sfax, Tunisia, namely 'Leg Extension', the 'Leg Curl' and 'Squat' were used. The training program was preceded by determining the maximum repetition (RM-1) at each unit. The 1-RM was adjusted after every four weeks of training. During the first four weeks of training, light loads (60 and 70\% 1-RM), and the mode of concentric contraction, were imposed to prepare participants for the eccentric drive. For last weeks, the training was based on eccentric contractions with heavy loads $(100,110$ and $120 \%$ of 1-RM).Thus the athletes curb without blocking the movement resulted by the training charge during the downswing phase at each unit. Every athlete has only one session's test daily with a rest of 24 hours.

The dosage of testosterone among each athlete was always done before and after submission to physical programs at the antecubital vein in a restful sitting position. Each blood's sample was collected in a tube (EDTA) and frozen in nitrogen liquid at $-70^{\circ} \mathrm{C}$ before biochemical analysis. The Plasma concentrations of testosterone were determined in the laboratory of biochemistry at the University Hospital's center of Habib Bourguiba, Sfax by ELISA (Enzyme Linked Immunosorbent-Assay) according to the method described by Singh et al. (2011). The normal range was calibrated and then $25 \mu l$ serum samples were taken in the well plates.

$100 \mu \mathrm{l}$ of enzyme conjugate was added in each well. After that, it was left for incubation at $37^{\circ} \mathrm{C}$ in incubator for 1 hour. Then, the wells were washed with $300 \mu$ distilled water for at least 3 times and blotted. Then, $100 \mu \mathrm{l}$ TMB solution was added as substrate in each well plate and was again left for the incubation for 15 minutes for the color. Finally, $100 \mu$ s stop solution was added in each well to stop the reaction. Reading was taken at $630 \mathrm{~nm}$ through Merck ELISA reader in $\mathrm{ng} / \mathrm{ml}$ value.

The Analysis of variance (ANOVA) of results was made following a randomly complete block design (Snedecor and Cochran, 1957) by the GLM procedure of the SAS statistical package (SAS Institute, 1989). Homogeneity of variance was verified by the standard Bartlett test (Anderson and McLean, 1974).

\section{Results}

The mean values of serum testosterone concentrations measured in the morning, the noon or in the evening before and after physical training in eccentric among athletes are presented in figs 1 and 2.

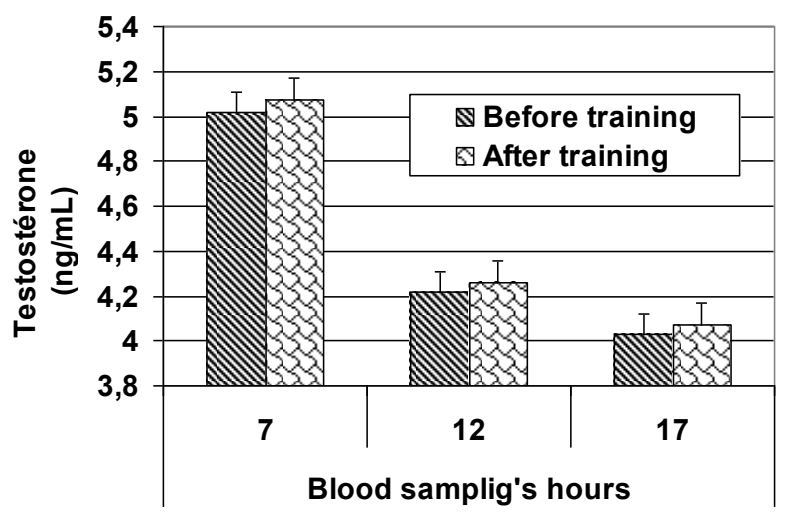

Figure 1: Daily evolution of plasma testosterone athletes before and after submission to physical eccentric training between 7 and 8 o'clock in the morning. Vertical bar show average \pm SD for 30 .

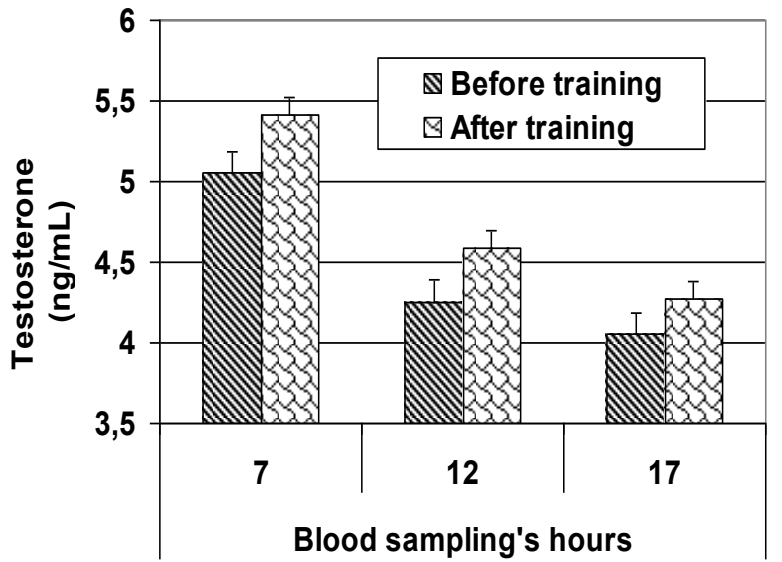

Figure 2: Daily evolution of plasma testosterone among athletes before and after submission to physical eccentric training between 16 and 17 o'clock in the evening. Vertical bar show average \pm SD for 30. 
The submission of athletes to an eccentric physical training in the morning or in the evening for three months increased plasma testosterone concentrations compared to respective controls (Figs 1 and 2) with $\mathrm{P}<$ .01 . However, this increase appears to be significantly just in the group of athletes who have always training in the evening with $\mathrm{P}<.01$.

The plasma testosterone concentrations decreased significantly during the day and this for the athletes trained either in the morning or in the evening as well as their respective controls $(\mathrm{P}<.001)$ (Figs 1 and 2$)$. However, the fall of the levels of this hormone seems to be more pronounced among the athletes who have been subjected to physical training in the morning $(\mathrm{P}<.001)$.

\section{Discussion}

It is well established that strength training among men who practiced weightlifting or bodybuilding stimulate the growth of muscle mass and that it is often positively correlated with the serum concentration of chronic testosterone (Bhasin et al., 2001; Kvorning et al., 2006). This hormone, which could be of testicular or adrenal origin, involved in the stimulation of protein synthesis, often has a peak activity at night (Touitou and Haus, 2000). Thus, the measurement of plasma concentrations of testosterone can account for circadian variations of anabolic status of muscle areas (Bird and Tarpenning, 2004).

Our study showed that the submission of athletes to eccentric physical training during eight weeks either in the morning or in the evening significantly increased plasma concentrations of testosterone base. This is consistent with the observations of Kramer et al. (2005) who reported that the sustained muscle activity but limited in time is often accompanied by a rapid rise in testosterone, which is distinct from that of other androgens, which often leads to periodic changes of chronic and non-testosterone levels which reflect the basic anabolic status of muscle tissue. The increased production of the androgen hormone in response to eccentric exercise might be the consequence of the reduction in plasma volume with hemo-concentration and increased blood viscosity, on the one hand, and an increase in testicular perfusion in the other hand. Similarly, CadouxHudson et al. (1985), in their work using radioactive testosterone, have been able to demonstrate that moderate increases in plasma testosterone response to moderate exercise are the result of decreased hepatic clearance.

Our results also showed that the plasma levels of testosterone decline in athletes trained or not, during the day, but faster for those who were still subject to eccentric exercise in the morning, which is consistent with results by Sedliak et al. (2007). Indeed, the decline rate of the anabolic hormone whose peak production was still observed at night could be attributed to shrug blood levels of cortisol (Cook et al., 2013).

\section{Conclusion}

Our study shows that the production of testosterone in athletes is largely influenced by the time of eccentric exercise. Indeed, it is the training evening that best promotes its production.

\section{References}

[1]. Anderson V.L., McLean R.L. 1974. Design of experiments. Marcel Dekker, New York.

[2]. Bernard T., Giacomoni M., Gavarry O., Seymat M., Falgairette G. 1998. Time-of-day effects in maximal anaerobic leg exercise. Eur. J. Appl. Physiol., 77, 133-138.

[3]. Bhasin S., Woodhouse L., Storer TW. 2001. Proof of the effect of testosterone on skeletal muscle. J. Endocrin., 1701, 27-38.

[4]. Bird S.P., Tarpenning K.M. 2004. Influence of circadian time structure on acute hormonal responses to a single bout of heavyresistance exercise in weight-trained men. Chronobiol. Int., 21, 131-46.

[5]. Cadoux H.T., Few J.D., Imms F.J. 1985. The effect of exercise on the production and clearance of testosterone in well trained young men. European Journal of Applied Physiology. 54, 1985, pp. 321-325.

[6]. Callard D., Davenne D., Gauthier A., Lagarde D., Van Hoeke J. 2000. Circadian rhythms in human muscular efficiency: Continuous physical exercise versus continuous rest. A crossover study. Chronobiol. Int., 17, 693-704.

[7]. Cook C.J., Liam P., Kilduff L.P., Crewtherc B.T., Beavenf M., Westb D.J. 2013. Morning based strength training improves afternoon physical performance in rugby union players. J. Sci. Med. in Sport. (In press).

[8]. Falgairette G., Billaut F., Ramdani S. 2003. Durée de la récupération et puissance maximale anaérobie au cours de la journée. Can. J. Appl. Physiol. 28, 213-224

[9]. Ferrando A.A., Tipton K.D., Doyle D., Phillips S.M., Cortiella J., Wolfe R.R. 1998. Testosterone injection stimulates net protein synthesis but not tissue amino acid transport. Amer. J. Physiol. Endocrinol. Metab., 275, 864-871.

[10]. Gauthier A., Davenne D., Martin A., Van Hoeke J. 2001. Time of day effects on isometric and isokinetic torque developed during elbow flexion in humans. Eur. J. Appl. Physiol., 84, 249-252.

[11]. Gutenbrunner C. 1993. Circadian variation in physical training. In Chronobiology and Chronomedicine (Edited by C. Gutenbrunner, G. Hildebrandt and R. Moog). p 665-680. Frankfurt: Peter Lang.

[12]. Hill D.W., Cuerton K.J.,Collins M.A. 1989.Circadian specificity in exercise training. Ergonomics, 32, 79-92.

[13]. Kraemer W.J., Marchitelli L., Gordon S.E., Harman E., Dziados J.E., Mello R., Frykman P., McCurry D., Fleck, S.J. 1990. Hormonal and growth factor responses to heavy-resistance exercise protocols. J. Appl. Physiol., 69, 1442-1450.

[14]. Kraemer W.J., Ratamess N.A. 2005. Hormonal responses and adaptations to resistance exercise and training. Sports Med., 35, 339361 .

[15]. Kvorning T., Bagger M., Caserotti P., Madsen K. 2006. Effects of vibration and resistance training on neuromuscular and hormonal measures. Eur. J. Appl. Physiol., 96, 615-625 
[16]. Nindl I., Arndt R., Schneede P., Enno C., Eggert S., Meyer T. 2001. Low oncogenic potential of HPV53 examined in patients with normal cytology, condylomata acuminata, CIN and cervical cancer. Proceedings of the 19th International Papillomavirus Conference. Paris, Vol. 20.

[17]. Racinais S, Connes P, Bishop D, Blonc S, Hue O. 2005. Morning versus evening power output and repeated-sprint ability. Chronobiol. Int., 22, 1029-39.

[18]. Sedliak M., Finni T., Cheng S., Kraemer W.J., Häkkinen K. 2007. Effect of time-of-day-specific strength training on serum hormone concentrations and isometric strength in men. Chronobiol. Int., 24, 1159-1177

[19]. Sale D.C. 1992. Neural adaptation to strength training. In: Komi PV, ed. Strength and power in sport. Oxford: Blackwell Science. Pp. 249-265.

[20]. Sale D., Mac Dougall D. 1981. Specificity in strength training: A review for the coach and athlete. Canadian J. Appl. Sports Sci., 2, 87-92.

[21]. SAS Institute, 1989. SAS/STAT User's Guide, ver. 6, vol. 2, 4th ed. SAS Institute, Cary, N.C.

[22]. Snedecor G.W., Cochran W.G. 1957. Statistical Methods. 6th ed. Iowa State Univ Press.

[23]. Singh J.K., Nath A., Kumar A., Md. Ali M., Kumar R. 2011. Study on the effect of endosulfan on testosterone level and somniferous tubule of testis of mice. World J. Envir. Poll., 1, 1-4.

[24]. Souissi N., Gauthier A., Sesbou, B., Larue J., Davenne D. 2002. Effects of regular training at the same time of day on diurnal fluctuations in muscular performance. J. Sports Sci., 20, 929-937.

[25]. Souissi N., Sesboue B., Gauthier A., Larue J., Davenne D. 2003. Effects of one night's sleep deprivation on anaerobic performance the following day. Eur. J. Appl. Physiol., 89, 359-366.

[26]. Touitou Y., Haus E. 2000. Alterations with aging of the endocrine and neuroendocrine system in humans. Chronobiol. Int., 17, 369390.

[27]. Yildirim B.O., Derksen JL. 2012. A review on the relationship between testosterone and life-course persistent antisocial. Psych. Res., 200, 984-2010.

[28]. Singh J.K., Nath A., Kumar A., Md. Ali M., Kumar R. 2011. Study on the effect of endosulfan on testosterone level and somniferous tubule of testis of mice. World J. Envir. Poll., 1, 1-4. 